\title{
Comparison of the cascadability of conventional and gain-clamped semiconductor optical amplifier gates in multi wavelength optical networks
}

\author{
Wolfson, David; Stubkjær, Kristian Elmholdt
}

Published in:

The Technical Digest of OFC'99

Link to article, DOI:

10.1109/OFC.1999.765990

Publication date:

1999

Document Version

Publisher's PDF, also known as Version of record

Link back to DTU Orbit

Citation (APA):

Wolfson, D., \& Stubkjær, K. E. (1999). Comparison of the cascadability of conventional and gain-clamped semiconductor optical amplifier gates in multi wavelength optical networks. In The Technical Digest of OFC'99 IEEE. https://doi.org/10.1109/OFC.1999.765990

\section{General rights}

Copyright and moral rights for the publications made accessible in the public portal are retained by the authors and/or other copyright owners and it is a condition of accessing publications that users recognise and abide by the legal requirements associated with these rights.

- Users may download and print one copy of any publication from the public portal for the purpose of private study or research.

- You may not further distribute the material or use it for any profit-making activity or commercial gain

- You may freely distribute the URL identifying the publication in the public portal 


\title{
Comparison of the cascadability of conventional and gain-clamped semiconductor optical amplifier gates in multi wavelength optical networks
}

\author{
D. Wolfson and K. E Stubkjaer
}

\begin{abstract}
Center for Broadband Telecommunications, Dept. of Electromagnetic Systems. Technical University of Denmark, Bldg. 348, DK - 2800 Lyngby, Denmark Telephone: +45 458814 44, Fax: +45 459316 34, e-mail: dw@emi.dtu.dk
\end{abstract}

Introduction: Photonic switch blocks in all-optical networks will need space switches. Contrary to many other types of gates and switches, semiconductor optical amplifiers (SOA) are attractive as gates since they feature the high on-off ratios of $40-50 \mathrm{~dB}$ that are needed to overcome the severe penalty induced by crosstalk [1]. At the same time they compensate for switch block losses. The input power dynamic range (IPDR) of the SOA-gate is, however, limited by spontaneous emission at low input powers and extinction ratio degradation due to gain saturation at high input powers [2]. This will severely restrict the number of switch blocks that can be cascaded. In order to reduce the influence of the extinction ratio degradation, a gain-clamped SOA (GC-SOA) has been proposed [3] for which the gain is clamped by a laser oscillation inside the amplifier resulting in a higher IPDR.

Here, we asses the cascadability of conventional SOAs and GC-SOAs in a WDM network using a detailed theoretical model. The analysis shows far superior cascadability of GC-SOAs at a channel bit rate of 2.5 $\mathrm{Gbit} / \mathrm{s}$ in systems with up to at least 16 channels.

Device structures and comparison conditions: The superior performance of the GC-SOA is due to a higher saturation input power. This is illustrated in Fig. 1 [4], showing the measured and calculated gain versus signal input power for a $450 \mu \mathrm{m}$ long conventional SOA (structure described in [2]) and a $1000 \mu \mathrm{m}$ long GC-SOA (described in [5]). Note, the excellent agreement between measurements and theory. As can be seen in Fig. 1, the gain of a conventional SOA decreases as the input power increases, whereas, the gain of the GC-SOA remains constant until the amplified signal is comparable to the power of the lasing mode. Furthermore, as described in [6] and shown in Fig. 1, increasing the bias current results in an increased saturation input power, while the unsaturated gain remains constant. As a result, larger IPDR can be

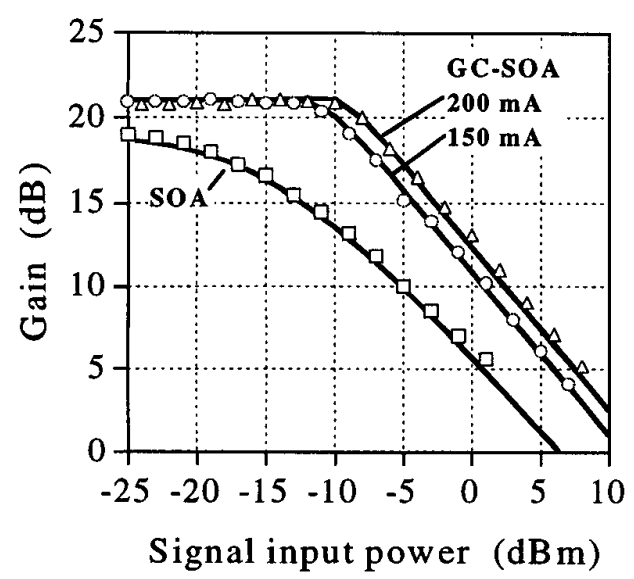

Fig. 1 Measured (dots) and calculated (lines) gain as function of the input power for a $450 \mu \mathrm{m}$ long SOA operated at $40 \mathrm{~mA}$ and a $1000 \mu \mathrm{m}$ long GC-SOA operated at 150 and $200 \mathrm{~mA}$. The GC-SOA is realised as a DBR lasezwith two Bragg regions of lengths 200 $\mu m$ and an active region of length $600 \mu \mathrm{m}$. obtained using GC-SOAs biased at high currents compared to conventional SOAs [4]. In order to make a fair comparison between the GC-SOA and the conventional SOA, equal unsaturated gains of 21 $\mathrm{dB}$ are used. This is accomplished by shortening the device length of the SOA from $450 \mu \mathrm{m}$ to $250 \mu \mathrm{m}$. We emphasise, that this is in favour of the SOA since a short SOA has a lower noise figure and a higher saturation input power compared to a long SOA [2].

Results: The static gain characteristics shown in Fig. 1, which is for a single wavelength, predict a superior dynamic performance of the GC-SOA in a multi wavelength system. This is verified in Fig. 2, showing the extinction ratio at the output of the gates versus signal input power per channel at 2.5 and 10 Gbit/s for the conventional SOA (Fig. 2.a) and the GC-SOA (Fig. 2.b). The calculations are performed with 4 and 8 channels with a $2 \mathrm{~nm}$ channel spacing, which is seen as a realistic approach in a multi 
channel system. We emphasise, that the channels are modulated independently of each other (NRZ-format). Furthermore, the input extinction ratio of all channels is $13 \mathrm{~dB}$, while the shown output extinction ratio is that of channel 1 .

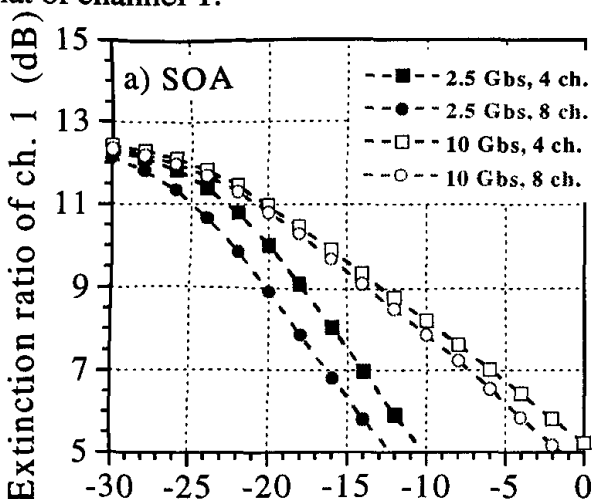

Signal input power per channel $(\mathrm{dBm})$

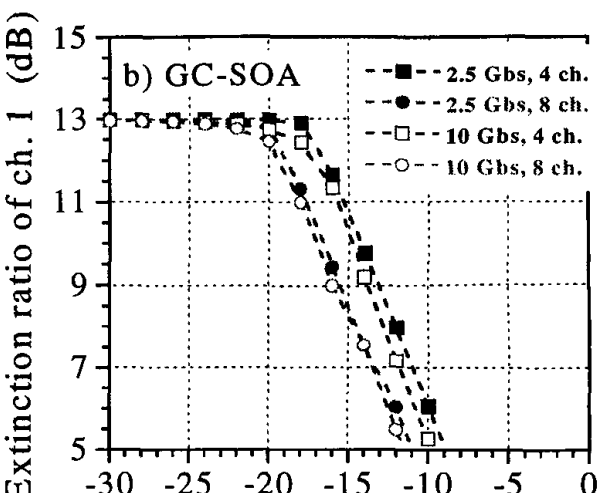

Signal input power per channel $(\mathrm{dBm})$

Fig. 2 Calculated extinction ratio at the output of the a) SOA and b) GC-SOA (biased at $200 \mathrm{~mA}$ ) as function of the signal input power per channel with the number of channels and the channel bit rate as a parameter. The channel spacing is $2 \mathrm{~nm}$ and input extinction ratio for all channels is $13 \mathrm{~dB}$.

A fundamental difference between the SOA and the GC-SOA can be seen in Fig. 2. For the SOA, the extinction ratio decreases as the signal input power increases or the number of channels increases. However, increasing the channel bit rate to $10 \mathrm{Gbit} / \mathrm{s}$ improves the extinction ratio since the influence of gain modulation from other channels becomes less pronounced. For the GC-SOA, there is no degradation of the extinction ratio before the amplifier starts to saturate but in contrast to the conventional SOA, there is no improvement by increasing the channel bit rate. This is due to the limited (13-14 GHz) relaxation frequency of the GC-SOA, which causes pulse pattern effects that limits the performance [4],[6]. Nevertheless, for input powers below the saturation point of the GC-SOA, clearly the SOA performance is worst.

In WDM networks several space switches will be concatenated. Therefore, the cascadability of optical gates is important. The superior dynamic characteristics of the GC-SOAs in a multi wavelength system, as seen in Fig. 2, can be used to substantially increase the cascadability of optical switches. This is illustrated

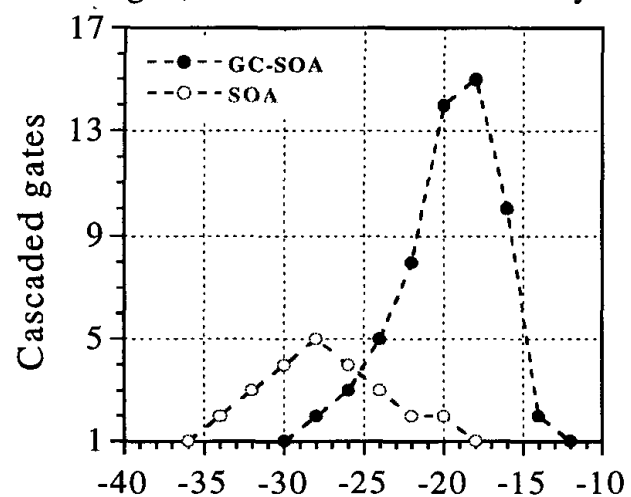

Signal input power per channel $(\mathrm{dBm})$

Fig. 3 Number of GC-SOAs and SOAs that can be cascaded (@1dB penalty) as function of the signal input power per channel (using 4 channels with $2 \mathrm{~nm}$ channel spacing). The channel bit rate is $2.5 \mathrm{Gbit} / \mathrm{s}$. in Fig. 3, showing the number of GC-SOAs and SOAs that can be concatenated (@ $1 \mathrm{~dB}$ penalty) versus the signal input power per channel. The calculations are performed with 4 channels at a channel bit rate of $2.5 \mathrm{Gbit} / \mathrm{s}$. As seen in Fig. 3, a higher number of SOAs can be concatenated at low input powers. This is because the SOA has a noise figure of only $\sim 5 \mathrm{~dB}$, while the GC-SOA has a noise figure of $\sim 11 \mathrm{~dB}$. The higher noise figure of the GCSOA is due to a longer amplifier section and the passive Bragg region in the front of the amplifier. Since the cascadability at low input powers is limited by ASE accumulation rather than extinction ratio degradation, the lower noise figure for the SOA results in better performance. Increasing the input power increases the signal-to-noise ratio and consequently the cascadability of both types of gates. 
At high input powers, however, the extinction ratio degradation becomes a limiting factor as shown in Fig. 2. This is much more severe in SOAs compared to GC-SOAs. Therefore, far superior performance is achieved for the GC-SOA as shown in Fig. 3 even when compared to a short cavity SOA gate. As seen, 15 GC-SOAs can be cascaded (@ input power of $-18 \mathrm{dBm}$ per channel), compared to a maximum of only 5

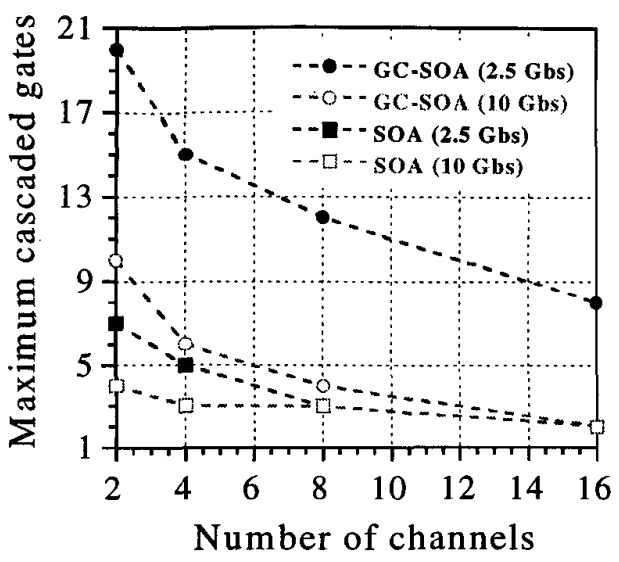

Fig. 4 Maximum number of GC-SOAs and SOAs that can be cascaded (@IdB penalty) as function of the number of channels. The channel bit rate is $2.5 \mathrm{Gbit} / \mathrm{s}$ and $10 \mathrm{Gbit/s}$, while the channel spacing is $2 \mathrm{~nm}$.
SOAs (@ input power of $-28 \mathrm{dBm}$ per channel). This makes GC-SOA gates very attractive for large scale optical networks, where cascadability is an important issue. The superior performance is also illustrated in Fig. 4 showing the maximum number of GC-SOAs and SOAs that can be cascaded (@1 dB penalty) at 2.5 and $10 \mathrm{Gbit} / \mathrm{s}$ as function of the number of channels. As seen in Fig. 4, the use of GC-SOAs at $2.5 \mathrm{Gbit} / \mathrm{s}$ allows a much higher number of gates to be cascaded.

At a channel bit rate of $10 \mathrm{Gbit} / \mathrm{s}$, the ASE accumulation starts to become a limiting factor for the cascadability. Furthermore, the influence of the relaxation oscillations in GC-SOAs also limit the performance [4],[6]. This is evident from Fig. 4, where the cascadability of both gates has decreased and even more important the improvement in cascadability of the GC-SOA compared to the conventional SOA has also decreased. Still, the GC-SOA performs equal or even better at $10 \mathrm{Gbit} / \mathrm{s}$ compared the short cavity SOA at $2.5 \mathrm{Gbit} / \mathrm{s}$.

Conclusion: A detailed theoretical investigation of the cascadability of conventional SOAs and GC-SOAs has been carried out in an optical multi channel system. It has been shown that the extinction ratio degradation experienced in a SOA increases as the input power or the number of input channels increases, whereas, there is no extinctio ratio degradation in the GC-SOA independently of the input power or the number of input channels until the amplifier saturates. Thereby, superior cascadability is achieved for the GC-SOAs, even compared to short cavity SOA gates, making them very attractive for network applications where high switching speeds and cascadability are required. The advantages are, however, reduced at high bit rates due to a limited relaxation frequency. Therefore, it will be an important challenge to fabricate GCSOAs with high relaxation frequencies needed for high speed operation.

\section{References:}

[1] E. Goldstein et al., IEEE Photonic Technology Letters, Vol. 6, No. 5, pp. 657-660, 1994.

[2] B. Mikkelsen et al., Proc. of ECOC'94, Vol. 2, pp. 710-713, Florence, Italy, 1994.

[3] G. Soulage et al., Proc. of ECOC'94, Vol. 1, pp. 451-454, Florence, Italy, 1994.

[4] S. L. Danielsen et al., Proc. of OFC'98, paper TuH2, San Jose, USA, Feb. 1998.

[5] G. Soulage et al., Proc. of ECOC'96, Vol. 4, pp. 145-148, Oslo, Norway, 1996.

[6] D. Wolfson et al., IEEE Photonic Technology Letters, Vol. 10, No. 9, pp. 1241-1243, 1998. 